\title{
¿Por qué la mediación es un buen instrumento para resolver conflictos civiles en tiempos de COVID-19 y post-COVID-19?
}

\author{
Dra. Carmen Barrón López*
}

Universidad de Valencia

Carbalo2@alumni.uv.es

Código ORCID: https://orcid.org/0000-0002-2539-307X

\section{Resumen:}

El colapso generado por la pandemia del COVID-19 en el funcionamiento de la Administración de Justicia por la suspensión de las actuaciones judiciales junto con la previsión de un aumento de la litigiosidad provocada por la situación económica derivada de la misma han propiciado la necesidad de replantear los sistemas actuales de tutela judicial. Desde el ámbito interno se está propiciando por el Consejo General del Poder Judicial la incorporación efectiva de la mediación como cauce de resolución de los conflictos. Situaciones de crisis de la justicia como la actual deben ser determinantes para el impulso efectivo de la mediación como vía idónea para la gestión y solución de conflictos civiles, a la que habría que acudir de forma preferente a la vía judicial en tiempos de COVID-19 y post-COVID-19.

Palabras clave: crisis; justicia; ADR; mediación; conflictos civiles

\begin{abstract}
:
"Why is mediation a good instrument to resolve civil conflicts in times of COVID19 and post-COVID-19?". The collapse generated by the COVID-19 pandemic in the functioning of the Administration of Justice by the suspension of judicial proceedings, together with the forecast of an increase in litigation caused by the economic situation resulting from it, have favored the need to rethink the current judicial guardianship systems. From the domestic level, the General Council of the Judiciary is favoring the effective incorporation of mediation as a channel for conflict resolution. Situations of justice crises, such as the current one, must be decisive for the effective promotion of mediation as an ideal way for the management and resolution of civil conflicts, which should be used preferably to judicial channels in times of COVID-19 and post-COVID19.
\end{abstract}

Keywords: crisis; justice; ADR; mediation; civil conflicts

Recibido: 15.10 .2020

Aceptado: 07.12.2020

\footnotetext{
* Doctora en Derecho, Departamento de Derecho Procesal de la Universitat de València (UV). Máster en Derecho, Empresa y Justicia por la UV. Accésit del Premio Tomás y Valiente de la Facultad de Derecho de la UV a los mejores trabajos de investigación jurídica 2018. Abogada en ejercicio.
} 


\section{Introducción}

En estos días nos hemos visto sumergidos en una nueva realidad, motivada por la irrupción a nivel mundial de la pandemia por la COVID-19, que nos está afectando en muy diversos ámbitos. Las situaciones vividas en los últimos meses han tambaleado nuestros cimientos sanitarios, políticos, judiciales y socioeconómicos. Así, la incesante actividad de nuestro día a día se ha visto paralizada de forma drástica hasta límites que, desde el punto de visto psicológico -e incluso jurídico- resultaban insospechados, de forma que nuestra libertad de actividad y de movimiento ha cedido en favor de la seguridad general, bajo la amenaza de un riesgo sanitario latente. En estas circunstancias, la prioridad sanitaria ha dirigido la actividad legislativa gubernamental, que se ha centrado en dictar sucesivas medidas urgentes a fin de paliar la crisis sanitaria y sus efectos socioeconómicos colaterales.

Asimismo, la pandemia del COVID-19 en España ha incidido especialmente en el funcionamiento de la Administración de Justicia, tras la declaración del estado de alarma el 14 de marzo de 2020, con la suspensión general de términos y plazos procesales, salvo para las imprescindibles actuaciones judiciales. En suma, junto a esta situación, hay que añadir que, tras la reanudación de la actividad judicial, se ha producido un exponencial aumento de la litigiosidad provocado por el impacto de la pandemia en nuestra economía. Ante esta realidad, se ha evidenciado una profunda crisis de la Administración de Justicia que pone de manifiesto la oportunidad, e incluso la necesidad, de replantear nuestro modelo judicial y buscar mecanismos que, junto con la vía judicial, configuren un sistema plural de vías de acceso a la Justicia, sin perjuicio de que la Administración de Justicia demuestre su capacidad de adaptarse a las nuevas circunstancias concurrentes.

Ciertamente, los efectos colaterales de la pandemia se dibujan devastadores en nuestro panorama socioeconómico, teniendo una gran repercusión conflictual la suspensión de la actividad económica, así como la dificultad de retomarla en un escenario económico inestable, impregnado por una constante amenaza sanitaria.

Pues bien, ante esta nueva realidad surgen oportunidades de cambio en el ámbito judicial que no debemos dejar pasar. Es por ello que debemos plantearnos soluciones y buscar alternativas constructivas que ayuden a paliarla. Centrándonos ya en el ámbito conflictual, la paralización de la actividad económica motivada por la declaración del estado de alarma y las dificultades para retomarla con normalidad son el caldo de cultivo de múltiples situaciones conflictuales que comienzan a invadir nuestro sistema judicial. En línea con lo expuesto, a diferencia de periodos anteriores de crisis económica en España, más focalizados en determinados sectores de la actividad, el impacto socioeconómico de la pandemia ha sido generalizado y ha afectado plenamente el tejido empresarial y la actividad económica de nuestro país, lo que irremediablemente está derivando en múltiples situaciones de endeudamiento de las familias y de insolvencia empresarial.

En razón a lo expuesto, el número de procedimientos judiciales en el ámbito civil está creciendo exponencialmente, sin que haya previsiones de que dicha situación a corto plazo vaya a mejorar, por lo que se dibuja un oscuro panorama judicial.

\section{Status quo de la mediación en España}

La incorporación de las ADR en nuestro modelo continental atiende al reto de los países democráticos de facilitar el acceso a la Justicia del ciudadano, 
proporcionándole un sistema adaptado a las necesidades evolutivas de la nueva realidad económica y social. Esta corriente ha venido impulsada por su reconocimiento nivel nacional e internacional, con denominaciones como MARC (Métodos Alternativos de Resolución de Conflictos), MASC (Métodos Alternativos de Solución de Conflictos) y RAC (Resolución Alternativa de Conflictos) (Barona Vilar, 2014, p. 11).

La incardinación de mecanismos como la conciliación, la mediación o el arbitraje en un nuestro modelo de Justicia coexistiendo con los tribunales, en la actualidad, es una realidad indiscutida. De esta forma, estos mecanismos, en su evolución, se han venido posicionando como piezas esenciales en Derecho privado para la resolución de los conflictos, configurando un paradigma de justicia eficaz que ha cambiado su visión inicial de vías alternativas a la judicial, hasta su consideración como vías complementarias (Barona Vilar, 2011, p. 188).

En palabras de Redorta Lorente "el acceso a la Justicia por los ciudadanos debe ser visto como el derecho de acceso a los medios apropiados de resolución de conflictos en función de las circunstancias del caso" (Redorta Lorente, 2009, p. 6).

En este punto, resulta ya incuestionable que, aunque los tribunales han sido la única vía planteada para la resolución de conflictos, se han impulsado doctrinalmente otras vías de acceso a la Justicia, surgidas inicialmente como repulsa a la vía judicial, para posteriormente instaurarse como su complemento. Esta corriente es fiel reflejo del estado de bienestar que avanza en la búsqueda de proporcionar al ciudadano servicios públicos de calidad, entre los que se encuentra un sistema satisfactorio de acceso a la Justicia.

\section{Compartimos con Barona Vilar que:}

"La sociedad neo-moderna ha truncado el principio de que solo hay tutela bajo el monopolio procesal y con los tribunales de justicia. La paulatina incorporación -primero sectorial y poco a poco más general- de las ADR (inicialmente Alternative Dispute Resolution y posteriormente Adequated Dispute Resolution), amén de las mismas con instrumentos tecnológicos que han dado lugar a las ODR (On line Dispute Resolution), ha favorecido este cambio en el modelo de Justicia del Siglo XXI y ha avanzado hasta la consideración actual de todos los instrumentos de tutela de los ciudadanos, judiciales y no judiciales, jurisdiccionales y no jurisdiccionales, en un concepto de 'Justicia integral' o lo que en el mundo anglosajón se vino considerando como la multi-rooms Justice System" (Barona Vilar, 2018, p. 438).

En este escenario, las ADR han incitado una visión integral de la Justicia que ofrece al ciudadano un nuevo modelo amparado en el derecho a la tutela judicial efectiva. Así, junto al modelo judicial establecido por el Estado, se plantea la utilización paritaria de mecanismos de intervención privada como la mediación, en el que cobran especial protagonismo las partes.

En línea con lo expuesto, un sistema de justicia plural pone de relieve las ventajas de la aplicación en la resolución de controversias de sistemas de autotutela, autocomposición y otros mecanismos de heterocomposición (Moreno Catena, 2017, p. 50). Sobre la cuestión expuesta, compartimos con Martin Diz que:

"El modelo de justicia estrictamente procesal y estatalizado, en alusión a que la vía única y exclusiva de resolución de litigios, de acceso a la justicia, sea el proceso judicial dispuesto desde la Administración de Justicia ofrecida por el 
Estado ha de superarse. No cabe, ya desde hace siglos, aún sin reflejo constitucional expreso, un modelo de justicia unívoco, un modelo en que la única forma de tutela pacífica y jurídica de los derechos sea el proceso judicial y a través de la función jurisdiccional que desempeñan jueces y magistrados pertenecientes al Poder Judicial. Nos encontramos en plena transición hacia una justicia integral en la cual conviven los sistemas jurisdiccionales públicos y dependientes del Estado con mecanismos extrajudiciales de resolución de conflictos..." (Martín Diz, 2019, p. 27).

Entre los citados mecanismos, consideramos de especial trascendencia la mediación, institución sobre la que resulta difícil dar una definición integradora (Soleto Muñoz, 2009, pp. 66-88) y que, si bien no es de reciente creación, en la actualidad más que una novedad es ya una realidad en España (Martín Diz, 2014, p. 2),

La mediación ha sido impulsada en nuestro país a instancia de la Unión Europea (UE) y de otros movimientos interregionales que la consideran una vía idónea para la gestión y resolución de conflictos. Este interés por la mediación no conlleva que su implantación haya sido efectiva, al estar siendo más costosa de lo que probablemente las autoridades de la UE pensaron y no haber alcanzado la finalidad esperada -en contraste con otros países de nuestro entorno-.

\section{Incorporación de la mediación en las normas de Derecho español}

El punto de partida para la regulación de la mediación en España tuvo lugar en el ámbito europeo con la Directiva 2008/52/CE del Parlamento Europeo y del Consejo de 21 de mayo de 2008, sobre ciertos aspectos de la mediación en asuntos civiles y mercantiles, en adelante, Directiva 2008/52/CE.

La Directiva 2008/52/CE constituye la culminación del interés mostrado por parte de la UE por los sistemas ADR y su transposición al ordenamiento jurídico español (Azcárraga Monzonís, 2013, p. 3) al establecer la obligación de los Estados miembros de la UE de legislar sobre mediación civil y mercantil.

En España, la transposición de esta Directiva 2008/52/CE, cuya adopción era urgente, se produjo por la Ley 5/2012, del 6 de julio, de mediación en asuntos civiles y mercantiles (en adelante, Ley de Mediación), aplicable tanto a los conflictos transfronterizos entre los Estados miembros de la UE, como a los conflictos internos.

La Ley de Mediación define la mediación en su artículo 1 como "aquel medio de solución de controversias, cualquiera que sea su denominación, en que dos o más partes intentan voluntariamente alcanzar por sí mismas un acuerdo con la intervención de un mediador".

El ámbito de aplicación de la Ley de Mediación establecido en el artículo 2 extiende su aplicación a los asuntos civiles o mercantiles que versen sobre derechos y obligaciones disponibles, sin que resulte aplicable a la mediación en el ámbito penal, con las Administraciones públicas, en materia laboral y en conflictos de consumo.

Partiendo de la configuración de la mediación determinada por la Ley de Mediación, como rasgos esenciales de esta podemos destacar:

1. El principio de voluntariedad y de libre disposición para acudir a la mediación o para desistir de una mediación iniciada. 
El principio de voluntariedad, recogido en la Directiva 2008/52/CE, se fundamenta en la libre disponibilidad de las partes respecto al procedimiento, que les confiere poder de decisión para organizarlo y darlo por terminado en cualquier momento. Por tanto, la voluntariedad se configura como un principio esencial de la mediación basado en el poder de decisión de las partes sobre la gestión de sus conflictos, lo que fomenta la responsabilidad de las partes y la toma de conciencia sobre las consecuencias de los acuerdos adoptados (Otero Parga, 2007, pp. 146-149).

2. Asimismo, el principio de igualdad entre las partes es trascendental en el procedimiento de mediación, en virtud del que se otorga a cada una de las partes la oportunidad de ejercitar sus derechos, proporcionándoles los mismos medios de defensa e intervención (Vilalta Nicuesa, 2009, pp. 43-44).

En la misma línea, compartimos con Barona Vilar que:

"sólo es posible identificar la mediación con la igualdad de las partes, de manera que, para que sean éstas las que intervengan, cedan y alcancen el acuerdo, es imprescindible que actúen en situación de igualdad de posiciones. De este modo, se viene excluyendo la mediación en aquellos supuestos en que este método implicaría la imposición de una parte sobre la otra, por razones diversas, de manera que deberán ser los mediadores los que establezcan esas situaciones claras que no deben llevarse a mediación" (Barona Vilar, 2010, p. 42).

3. El mediador debe ser neutral y adoptar una actitud cercana a las partes, pero equidistante respecto al acuerdo, siendo las partes las que lo alcancen. Por otra parte, la neutralidad es reflejo de la naturaleza autocompositiva de la mediación, en cuanto evidencia la capacidad y autonomía de las partes para gestionar el conflicto.

4. La mediación es un procedimiento flexible y adaptable a las circunstancias propias de cada conflicto y de las personas que intervienen en el mismo. Ciertamente, la mediación es un procedimiento flexible que se caracteriza por su adaptación a las necesidades de las partes, lo que no se deberá confundir con la arbitrariedad, por lo que, el mediador debe ser garante de que no se conculquen los principios de la mediación (Blohorn-Brenneur y Soleto Muñoz 2019, p.85).

En este sentido, el mediador tendrá la capacidad de valorar la marcha del procedimiento y adaptarlo, favoreciendo así el clima de acercamiento y confianza entre las partes. Esta adaptación no sería posible en un procedimiento rígido y formulario que se centrase en considerar solo los aspectos objetivos del conflicto, sin evaluar el problema subyacente existente entre las partes.

5. El principio de confidencialidad es otro de los principios rectores de la mediación, sobre el que se asienta la confianza del ciudadano en el procedimiento. En definitiva, la confidencialidad genera el clima necesario para que las partes actúen con plena libertad, y, así, manifiesten sus intereses y realicen propuestas que puedan construir un acuerdo (García Villaluenga, 2010, p. 733).

Si bien, la mediación no ha tenido en España la finalidad esperada, ante lo que ha surgido una corriente doctrinal que propugna la obligatoriedad del intento de mediación, planteándolo como requisito previo de acceso a la vía judicial en supuestos tasados. En línea con dicha corriente, que estaría en consonancia con la regulación de la mediación en diversos países de nuestro entorno, el legislador español ha querido dar un nuevo enfoque a la mediación, planteado en el Anteproyecto de Ley de Impulso 
de la Mediación, aprobado el 11 de enero de 2019, estableciendo en supuestos tasados la obligatoriedad a los litigantes de acudir a una sesión informativa de mediación, en los seis meses previos a la interposición de la demanda.

Ciertamente, la citada propuesta legislativa ha supuesto un avance que plantearía un giro regulatorio de la mediación en España, estableciendo la obligatoriedad de las partes de acudir a la sesión informativa de mediación como trámite preceptivo en determinados procedimientos de ámbito civil y mercantil, así como en supuestos de mediación intrajudicial cuando sea acordada por el órgano judicial. Por tanto, nos encontramos ante una cuestión de gran trascendencia que, en caso de que finalmente sea implantada legislativamente en nuestro país, supondrá un importe cambio de rumbo en nuestro concepto de la mediación, al pasar de una mediación esencialmente voluntaria a convertirse en una mediación necesaria, pudiendo esta medida tener un efecto contrario al pretendido.

En este sentido, la obligatoriedad de la mediación como trámite procedimental previo a la vía judicial en determinadas materias y la sanción de condena en costas que acarrearía la incomparecencia injustificada de las partes, debe ser puesta en relación con el principio de voluntariedad de la mediación, a fin de considerar si dicha regulación pudiese conculcar el principio de libre acceso a la Justicia del ciudadano.

Sobre este punto, compartimos las conclusiones de Prats Albentosa:

"sin duda, el recurso directo a los Tribunales, sin intentar soluciones autocompositivas, no ha de estar vedado en ningún caso. No obstante, los litigantes deberían demostrar, efectivamente, al Juez, que han agotado todos los medios legítimos a su alcance para resolver el conflicto o que la gravedad de la lesión padecida es tal que, razonablemente, justifica que se acuda a ellos directamente. En consecuencia, los Tribunales deberían tratar con disfavor a quien no les demuestre que ha agotado todas las vías no judiciales para llegar a solucionar su litigio y, además, deberían tener a su alcance medios para reconducir el conflicto, cuando sea posible a tales vías de solución, sin que ello implique denegación de su ministerio, sino, al contrario, producirá un mejor ejercicio del derecho a la tutela judicial efectiva por los ciudadanos" (Prats Albentosa, 2011, pp.1-2).

En línea con lo anterior, la voluntariedad de la mediación no se considera conculcada por el hecho de acudir a la sesión informativa como fase previa al proceso, en cuanto, dicha asistencia brinda a las partes la oportunidad de conocer este método, sin imponerles la obligación de permanecer en el mismo; de modo que, las partes únicamente tendrán que asistir a la previa sesión informativa, a fin adquirir el conocimiento suficiente sobre esta técnica para, de esta forma, decidir sobre su utilización (García García, 2003, p. 137).

En posición contraria a dicha implantación surge una destacada corriente doctrinal que propugnan evolucionar hacia un derecho de tutela judicial efectiva que facilite al ciudadano acceder libremente a los órganos jurisdiccionales o a cualesquiera otras formas extrajudiciales de resolución de conflictos en el ejercicio de sus propios derechos e intereses legítimos, sin que para alcanzar una posición igualitaria en la elección de dichos métodos, deba imponerse la utilización obligatoria y condicionada de uno respecto al resto (Martín Diz, 2014, pp. 13-14).

Adicionalmente a lo expuesto -y como medida de impulso de la mediación en España-, se señala que el hecho de que las partes tengan que acudir a dicho 
mecanismo puede ser la oportunidad de conocer sus ventajas y existencia, al no ser suficiente su simple estímulo (Azcárraga Monzonís, 2016, pp. 103-117).

Ciertamente, nos encontramos ante una cuestión polémica en la que resulta difícil mantener una postura uniforme. Por una parte, respecto del trámite preceptivo de asistencia a mediación planteado como requisito indispensable de acceso a la vía judicial, consideramos que puede ser un efectivo impulso a la mediación, al acercarla al ciudadano y permitirle adquirir confianza en este método. Por otra parte, debemos considerar si la situación actual de la Administración de Justicia, unida a la desconfianza y reticencia del ciudadano al uso de la mediación son el escenario idóneo para que esta regulación puede cumplir la función pretendida, o si, por el contrario, su implantación lo convertiría en un trámite preceptivo que dificultase al ciudadano el libre acceso a la vía judicial y le encareciese sus costes.

\section{Impacto del coronavirus en la Administración de Justicia en España}

Ciertamente el modelo de Justicia de la era pre-coronavirus ya venía arrastrando múltiples deficiencias que se han incrementado por la crisis sanitaria y su impacto socioeconómico. En este escenario, tras la declaración del estado de alarma el 14 de marzo de 2020, nuestros tribunales han vivido una situación sin precedentes en nuestro país, motivada por la suspensión general de los términos y plazos procesales, salvo las actuaciones esenciales para garantizar los derechos de las personas. Pues bien, con la puesta en marcha de la maquinaria judicial tras el levantamiento de la suspensión, las instalaciones judiciales han tenido que acondicionarse para implantar medidas preventivas provocando estas en muchos casos la suspensión o imposibilidad de celebrar las vistas o actuaciones judiciales. La situación expuesta, a la que adicionalmente se une la más que previsible amenaza de un incremento de la litigiosidad en los diferentes ámbitos del Derecho afectados por esta nueva realidad socioeconómica, derivó en la aprobación del Real Decreto-Ley 16/2020, del 28 de abril, de medidas procesales y organizativas para hacer frente al COVID-19 en el ámbito de la Administración de Justicia.

La referida norma ha incorporado varias medidas de carácter procesal, de ámbito concursal, civil y mercantil con una doble finalidad: por un lado, facilitar una ágil reactivación de la actuación judicial tras el levantamiento de la suspensión y, por otro, la adopción de medidas previsoras del aumento de litigiosidad provocado por la pandemia.

En este sentido, las medidas adoptadas están orientadas a procurar la agilización procesal y mitigar el exceso de litigiosidad mediante el fomento de la mediación intrajudicial y la potenciación de mecanismos extrajudiciales de conflictos.

Amén de las referidas medidas de urgencia, la situación existente en nuestra Administración de Justicia evidencia la necesidad de adoptar soluciones de más amplio calado que excedan de la simple regulación por vía de urgencia de aspectos concretos, que enmienden de forma parcial nuestro ya deteriorado sistema judicial. En este sentido, resultan urgentes las medidas que garanticen la puesta al día de las actuaciones procesales atrasadas, con la inmediata celebración de las causas pendientes, así como las que garanticen una mayor celeridad de los nuevos procedimientos que están colapsando nuestros juzgados y tribunales.

Conscientes de dicha realidad, el Pleno del Consejo General del Poder Judicial, órgano de gobierno de los jueces, aprobó en junio de 2020 una serie de medidas denominadas Plan de Choque para la reactivación tras el estado de alarma declarado 
por el COVID-19, en el que se incluyen más de 60 medidas organizativas y gubernativas que recogen los principios y criterios generales que deberían inspirar las reformas legales a acometer.

Las medidas adoptadas recogen propuestas de muy diferente ámbito, desde organizativas y procesales, a tecnológicas y referentes a la solución extrajudicial de conflictos. En definitiva, las propuestas formuladas son un fiel reflejo del llamamiento que desde los diferentes ámbitos judiciales se está produciendo sobre la necesidad de implantar un nuevo modelo de Justicia en España.

En consecuencia, en situaciones como la actual, se demandan especialmente vías múltiples de acceso a la Justicia que garanticen un sistema más eficiente y que responda más ágilmente a las necesidades concretas del ciudadano y de la realidad social existente. De forma que, se ha de aprovechar la coyuntura de las circunstancias concurrentes para abordar una regeneración de la Justicia agónica, lo que requiere un replanteamiento del modelo paradigmático de Justicia (Barona Vilar, 2019, p. 779).

Ciertamente, la Administración de Justicia del siglo XXI, desconectada en gran medida de la realidad económica y social concurrente y sobrecargada por el auge de los conflictos derivados de un entorno cada día más complejo y globalizado, tiende a estar apoyada por medios extrajudiciales de resolución de litigios, tales como arbitraje, mediación y negociación, con un objetivo de justicia plural, integrada por sistemas alternativos o complementarios al proceso, sin que por ello se deba generar una situación de indefensión al ciudadano ${ }^{1}$.

\section{Mediación como instrumento idóneo de resolución de conflictos en tiempos de COVID-19}

Como hemos venido comentando en este trabajo, nos encontramos ante una situación excepcional y sin precedentes como ha sido reconocida en España por el propio Consejo General del Poder Judicial, destacando entre las medidas propuestas la necesidad de buscar fórmulas que incentiven la solución extrajudicial de conflictos y, de esta forma, reservar la intervención judicial para aquellos casos que realmente sea necesaria.

En línea con lo expuesto, en el ámbito procesal civil se está produciendo un incremento exponencial de la litigiosidad generada por los conflictos laborales, resoluciones o incumplimientos de contratos de alquiler de vivienda y local de negocio, conflictos surgidos en referencia a las medidas provisionales o definitivas acordadas en procedimientos de familia, incumplimientos contractuales fundamentados en un cambio imprevisto y drástico de las relaciones contractuales, impagos bancarios, etcétera. A esta larga relación de supuestos, tenemos que añadir de forma especial los conflictos generados en el ámbito empresarial, especialmente afectado por los efectos económicos derivados la pandemia.

En definitiva, se configura un oscuro panorama judicial, ante el que el modelo de justicia estrictamente procesalista implantado en España no ofrece una respuesta adecuada a los conflictos planteados, por ello, nos hemos de replantear nuestro modelo de Justicia, a fin de proporcionar al ciudadano un sistema de acceso dotado de vías que sean sensibles a la realidad socioeconómica existente y que atienda de forma rápida y efectiva la especial conflictividad surgida, aliviando con ello la sobrecarga de la vía judicial. 
Ciertamente, la pandemia ha sido el detonante para poner de manifiesto la insostenible situación de nuestra Administración de Justicia, reflejada en una creciente corriente doctrinal que reclama la implantación efectiva de mecanismos de resolución de conflictos como la mediación. No obstante, este camino abierto a otros cauces de resolución, con indudables concesiones respecto a una vía judicial monopolística de resolución de los conflictos, requiere un especial impulso para que se lleve a cabo la implantación efectiva de mecanismos como la mediación.

\section{En este sentido, compartimos con Martin Diz que:}

la mediación es una institución típicamente jurídica, en cuanto a su consideración como medio de resolución pacífica de disputas. Por tanto, en sentido amplio, ha de ser entendida como un mecanismo para impartir Justicia, que se inclina a dar a cada uno lo que le corresponde mediante la aplicación del derecho, la razón o la equidad (Martín Diz, 2010, p. 61).

Quizá la cuestión planteada debe trascender al método valorado y enfocarse desde una visión más general referente a la igualdad entre los diversos mecanismos de resolución de conflictos, partiendo de una regulación procedimental que garantice igualdad de armas y un efectivo derecho a la tutela judicial por los ciudadanos. Para ello, los diversos métodos, independientemente de su mayor idoneidad según la tipología del conflicto, podrán ser elegidos indistintamente por el ciudadano al inspirarle igual confianza y seguridad.

En razón a lo expuesto, a fin de valorar la idoneidad de la mediación, debemos considerar que el procedimiento de mediación es más flexible que el modelo judicial, al configurarse un procedimiento dinámico, en el que se determinan unos hitos mínimos y se deja libertad a las partes para su diseño y desarrollo, a fin de dotarlo de agilidad y especialidad. De modo que, en circunstancias como las concurrentes, consideramos que la mediación es el procedimiento que mejor puede adaptarse a las necesidades de las partes, sin que por ello se conculquen sus derechos y garantías esenciales.

En este sentido, como elementos rectores de la mediación podemos destacar los principios de voluntariedad, libre disposición, igualdad, confidencialidad y flexibilidad. Sobre la regulación del procedimiento de mediación sostiene Barona Vilar que:

"la regulación que se contiene en la Ley sobre el procedimiento no pretende tener vocación o carácter estático. De ser así, estaríamos ante una suerte de pseudoproceso al estilo del judicial, que no ofrecería ventajas a quienes a él acudan, más allá de la privatización de la justicia. No es ese ni el sentido de la incorporación de la mediación en el modelo de justicia y de tutela de los ciudadanos, ni el sentido per natura que tiene la mediación. La frescura, flexibilidad y adaptabilidad del procedimiento es su mayor tesoro, obviamente siempre que quien maneja el procedimiento, sea el mediador o mediadores, sea la institución de mediación, controlen y permitan extraer cuanto de beneficioso tiene esa adaptabilidad del procedimiento a las personas y a los conflictos" (Barona Vilar, 2013, p. 369).

En definitiva, el procedimiento de mediación es flexible y está regulado sobre unos parámetros básicos que dotan de validez al acuerdo alcanzado para darle fuerza ejecutiva, como refleja el apartado IV del Preámbulo de la Ley de Mediación.

Por todo ello, en las especiales condiciones concurrentes, hemos de considerar las bondades destacables de la mediación, como método que fomenta una cultura de 
diálogo, lo que lo perfila como un mecanismo idóneo, en razón a que cuenta con la flexibilidad y adaptabilidad necesaria para dar una respuesta a las diferentes situaciones conflictuales que se presenten, ofreciendo a las partes la posibilidad de alcanzar un consenso para solventar sus conflictos. De esta forma, las partes apoyadas por la figura del mediador podrán encontrar soluciones más adecuadas al contexto actual y a la verdadera situación de las partes, abogando por el mantenimiento de las relaciones de cualquier ámbito, afectadas por el conflicto.

En este punto, debemos considerar que el aumento de litigiosidad producido por la recesión económica derivada de la pandemia está saturando nuestro sistema judicial y que dicha situación se agravará paulatinamente al no intuirse una evolución positiva a medio o largo plazo. Adicionalmente a la situación expuesta, hay que añadir los efectos propios que las medidas preventivas sanitarias contra la COVID-19 están ocasionando en la dinámica habitual de nuestros tribunales, derivando en muchas ocasiones en la suspensión de las actuaciones judiciales por la inadecuación de las salas de vistas judiciales o por las deficiencias de los sistemas digitales implantados, así como por las bajas del personal motivadas por la enfermedad, etcétera.

Pues bien, el panorama expuesto nos hace plantearnos que, más allá de las esperadas medidas a adoptar en la Administración de Justicia basadas en el aumento de la plantilla judicial y la implantación efectiva de medios telemáticos que supongan un soporte en su estructura y dinámica de trabajo, el actual escenario socioeconómico y judicial ofrece la oportunidad, incluso la necesidad, de avanzar en la implementación efectiva de mecanismos de acceso a la Justicia, como la mediación.

En línea con lo anterior, la promoción de un sistema colaborativo de resolución de conflictos como la mediación, más allá de aliviar el colapso existente en nuestro sistema judicial, puede generar un sentimiento de autogestión y construcción autónoma de solución a los conflictos que evidencien un cambio de cultural y un aprendizaje social derivado de la situación existente.

En consecuencia, consideramos que la mediación debe implantarse e integrarse en la justicia civil como mecanismo idóneo para gestionar los conflictos surgidos especialmente a raíz de las circunstancias concurrentes. Su idoneidad radica en que su procedimiento permite un tratamiento específico del conflicto, con la finalidad de alcanzar una solución consensuada, con un consiguiente compromiso de cumplimiento de las partes de la solución alcanzada.

En definitiva, la mediación ofrece a los ciudadanos una herramienta que favorecerá una solución rápida, flexible, económica, privada y duradera. A pesar de ello, en la actualidad la mediación en España está poco implantada en el ámbito civil y mercantil y queda aún un largo camino por recorrer. En este sentido, la incorporación del estudio de la mediación en las universidades, así como, su fomento por instituciones y asociaciones nacionales y sectoriales es incuestionablemente el caldo de cultivo necesario para su futuro impulso. Asimismo, será decisivo para su fomento, el papel de los diversos operadores jurídicos, que deberán estar formados en este método para así transmitir la relevancia e idoneidad de su utilización.

La cuestión expuesta no es baladí, en cuanto la formación específica de estos profesionales, especialmente abogados y asesores que cuentan con la confianza de sus clientes, supondrá una nueva orientación en su asesoramiento, que estará dirigido a la mediación. Por tanto, para que la mediación pueda implantarse deberá superar el escollo previo de darse a conocer a los profesionales que asesoran, para que tomen conciencia de esta institución, en sus diversas dimensiones y conozcan las bondades 
de su implantación. De esta manera, su diligente actuación deberá estar orientada a proporcionar el mejor asesoramiento a sus clientes sobre los métodos más idóneos para gestionar sus conflictos, sin derivarlos necesariamente a la vía judicial.

Asimismo, el siguiente paso para el impulso de la mediación va de la mano del fomento efectivo de este instrumento en el ámbito empresarial. En este sentido, será necesario un acercamiento efectivo de la mediación a la empresa, mediante la demostración de sus virtudes y ventajas, de forma que inspire la confianza necesaria para recurrir a este método.

Por todo ello, para que la institución de la mediación se gane el respeto del justiciable, deberá transmitirle unos estándares de profesionalidad y transparencia que permitan confiar en esta institución y elegirla la mejor opción para gestionar y solventar determinados conflictos. En línea con lo expuesto, se ha de superar el temor en el uso de la mediación que, en definitiva, ofrece las mismas garantías y ejecutividad que la vía judicial.

Ciertamente, resulta incuestionable que la implantación efectiva de la mediación como mecanismo complementario a la vía judicial requerirá un cambio de cultura social, jurídica y normativa, para que este mecanismo se configure como medio efectivo de resolución de controversias. En consecuencia, será necesario un cambio de cultura, no sólo de los operadores jurídicos, sino también, de la ciudadanía en general y de la clase política en particular. Hace falta impulsar la mediación, observarla, seleccionar buenos mediadores, facilitar su acceso e integrarla en el marco de la tutela efectiva de los ciudadanos y, a partir de ahí, tratar de ir poco a poco adquiriendo fuerza en el marco de la gestión y resolución de conflictos.

\section{Protagonismo de la mediación en la era post-COVID-19}

Como hemos venido comentando en este trabajo, la situación existente provocada por los efectos socioeconómicos derivados de la pandemia ha agudizado la insostenible situación de nuestra Administración de Justicia que se encuentra desbordada y que evidencia su imposibilidad de atender la sobrecarga de trabajo derivada de esta nueva realidad.

En este contexto, entre las medidas propuestas por el Consejo General del Poder Judicial se encontraba la obligatoriedad de las partes de intentar una solución extrajudicial previamente al inicio de acciones civiles, cualquiera que fuere su cuantía.

Sin embargo, el Real Decreto-ley 16/2020 del 28 de abril, que publicó las medidas procesales y organizativas para hacer frente al COVID-19 en el ámbito de la Administración de Justicia, no acogió la referida recomendación del Consejo General del Poder Judicial. Ciertamente, en la actualidad, no se han adoptado medidas que de forma drástica pueda paliar la actual situación de nuestra Administración de Justicia. En este sentido, las medias de refuerzo de los juzgados y tribunales que atañen a la organización, planta y demarcación judicial, no se plantean como una solución efectiva a medio y largo plazo. Adicionalmente, aunque se ha producido un avance efectivo del proceso de digitalización de la Justicia, con la adaptación a las nuevas tecnologías implantadas con la Ley 18/2011 del 5 de julio, queda aún un largo camino por recorrer en este terreno.

En suma, la situación tiende a empeorar: cada día son más los procedimientos instados antes los tribunales y resulta patente la necesidad de los particulares y 
empresas de obtener una solución urgente a los conflictos económicos generados por la pandemia.

A sabiendas de que las esperadas medidas a adoptar por la Administración de Justicia resultarán a todas luces insuficientes para paliar el colapso judicial existente; se plantea un panorama que genera la necesidad urgente de adoptar medidas eficaces que dinamicen el acceso a la Justicia del ciudadano. En este punto, la mediación se perfila como una magnífica herramienta para dirimir conflictos derivados del impacto socioeconómico provocado por la pandemia, en cuanto, es el instrumento más idóneo para alcanzar acuerdos que puedan cumplirse y buscar una solución constructiva a la situación de confrontación.

Desde las empresas y familias se reclama la adopción urgente de un cambio de rumbo, ante la insostenible situación de nuestra Administración de Justicia. A la luz de esta nueva realidad que estamos viviendo, la mediación se perfila como un método especialmente idóneo en conflictos de ámbito civil o mercantil, lo que debería convertirla en la vía preferente para la gestión o resolución de los conflictos que se presenten en estos ámbitos. En este sentido, la naturaleza del conflicto debe ser un elemento determinante en la elección del método más adecuado para su tratamiento. De forma que, en las circunstancias concurrentes con especial incidencia en el sector empresarial, familiar y laboral, la mediación se convierte en el método más adecuado, fundamentalmente porque las partes pueden encontrar una solución equilibrada, más rápida, flexible y económica que la judicial, manteniendo a la vez el control de su cumplimiento.

En línea con lo expuesto, no podemos olvidar que la mediación se basa en el consenso dialogado y en la búsqueda de soluciones, sobre la base de un compromiso mutuo de cumplimiento de los acuerdos alcanzados. En este punto, dichos compromisos cobrarán especial significado para eliminar de forma efectiva el conflicto y evitar que surja a posteriori.

Como hemos venido comentando, desde el propio Consejo General del Poder Judicial se han elevado voces partidarias de la incorporación de la obligatoriedad de la mediación, en su sesión informativa, como paso previo para acceder a la vía judicial. Posiblemente, la adopción de dicha medida generaría una mayor cultura de la mediación, con la consiguiente reducción de la litigiosidad, pero también podría conculcar el principio de voluntariedad de la mediación, sin perjuicio de convertir dicho trámite en un presupuesto de procedibilidad necesario para acudir a la vía judicial (Barona Vilar, 2018, pp. 68-69).

En definitiva, debemos reconsiderar la fórmula de la denominada "mediación voluntaria mitigada" (Vázquez De Castro y García Villaluenga, 2013, p. 93). Este cambio de criterio se planteaba por el legislador al no haber conseguido la regulación actual de la mediación demostrar su operatividad, como expresamente manifiesta la Exposición de Motivos del referido Anteproyecto. Si bien, dicha fórmula no puede ser implantada como un remedio de urgencia, que tenga como finalidad primordial aliviar nuestro ahogado sistema judicial.

Ciertamente, se trataría de una obligatoriedad ope legis determinada por materias específicas que, asimismo, proporcionaría a los tribunales herramientas legales para derivar a mediación intrajudicial los asuntos que se consideren susceptibles de la misma. Cualquier reforma legislativa en estos términos debe ir adecuadamente acompañada de un esfuerzo institucional de impulso de la mediación que favorezca un cambio de cultura del ciudadano sobre dicho método. 
A modo de conclusión, en caso de que finalmente resulte aprobada alguna iniciativa legislativa en términos similares a los indicados, consideramos que su valoración como medida de impulso a la mediación puede ser positiva, al pretender la implantación definitiva de la mediación como un medio complementario a la vía judicial, relegando a ésta las cuestiones que no puedan obtener resolución por otras vías. Empero, dichos objetivos hay que ponerlos en relación con la situación actual de la mediación y su escasa implantación.

En línea con lo expuesto, para avanzar en este camino, consideramos que sería necesaria la previa difusión y puesta en valor de la mediación, a fin de que cuando las partes asistan a la reunión informativa, tengan ya conocimiento y confianza en este método, para verdaderamente planteárselo como una alternativa efectiva a la vía judicial. No obstante, este sería el primer paso, ya que, si el ciudadano no confía en este método, dicha asistencia se convertirá en un mero trámite procedimental que únicamente añadirá dilación temporal y coste económico al ya lento y gravoso procedimiento judicial.

Por tanto, consideramos que la eficacia de la mediación va más allá de adoptar medidas impositivas de ámbito legislativo, al ser fundamental para su implantación la potenciación de las políticas públicas que conciencien a la sociedad de sus virtualidades y la configuren como una vía efectiva de acceso a la Justicia. Esta concienciación, mediante la información y demostración de las bondades de este método, tendrá que ser extensiva a todas las partes implicadas, tanto a los diversos operadores jurídicos como jueces, abogados, etcétera-, como a las partes enfrentadas, para conseguir una implicación y compromiso conjunto en este procedimiento. De forma que es absolutamente imprescindible la concienciación de todos los profesionales del ámbito del Derecho y su colaboración decidida en apoyo de la mediación.

\section{Reflexiones finales}

Toda sociedad avanzada debe organizar sistemas que permitan ofrecer al ciudadano diversos mecanismos, entre los que pueda elegir libremente la vía más adecuada para la gestión y resolución de sus propios conflictos. En este sentido, ya se encuentra superada ampliamente la consideración de que el sistema judicial es la única vía de acceso a la Justicia, de forma que, incluso en determinados ámbitos conflictuales, han ido ganando peso métodos como el arbitraje o la mediación, que han pasado de ocupar una función alternativa a adoptar una posición complementaria, desplazando así a la vía judicial.

Como hemos venido comentando en este trabajo, estamos viviendo una situación de emergencia sanitaria mundial sin precedentes que ha traído consigo una fuerte recesión económica y, con ella, un exponencial incremento de la litigiosidad. Las desgraciadas circunstancias que nos han embargado han evidenciado las carencias de nuestro modelo de Justicia y su imposibilidad para atender y dar respuesta de forma rápida y efectiva a los conflictos generados en la era coronavirus y post-coronavirus.

Ante esta realidad, debemos plantear un cambio de rumbo que debe de ir inexorablemente unido de un efectivo impulso de las soluciones extra-jurisdiccionales de conflictos, con especial incidencia de la mediación, por su especial versatilidad en circunstancias como las concurrentes. En esta línea, el Consejo General del Poder Judicial ha adoptado medidas en favor de la potenciación y favorecimiento de la mediación. 
En estas circunstancias, no podemos dejar de impulsar la mediación, siendo para ello un soporte fundamental darla a conocer al ciudadano. Ciertamente, estamos viviendo momentos difíciles y de gran incertidumbre económica que exigen un replanteamiento de nuestro modelo de Justicia, en el que la mediación puede tener un especial protagonismo y configurarse como una pieza clave del sistema.

En el panorama existente, la mediación puede ser la mejor herramienta para afrontar las múltiples situaciones conflictivas que se planteen. La crisis económica generada por la pandemia está teniendo una fuerte repercusión socioeconómica que requiere un esfuerzo de reconstrucción laboral, familiar, económica y jurídica que proporcione a los conflictos surgidos una solución rápida y acorde a esta nueva realidad. En estas circunstancias, se ofrece una gran oportunidad a la mediación como vía que fomenta el consenso y la ayuda mutua. Por todo ello, será necesario confiar en la mediación y darle la oportunidad de desarrollar sus bondades.

Pese a todo ello, la mediación sigue careciendo en la actualidad en España de una regulación adecuada a nivel estatal que la desarrolle, la profesionalice y la dote de verdadera independencia funcional. Como hemos venido comentando, como medida para su implantación efectiva, va cogiendo fuerza la corriente doctrinal recogida en otros sistemas jurídicos, que ha tenido eco en el Anteproyecto legislativo mencionado, basado en imponer a las partes en determinados supuestos como requisito previo de procedibilidad para acceder a la vía judicial, la obligatoriedad de acudir a la sesión informativa del procedimiento de mediación.

De forma que, si el legislador finalmente adoptase este cambio de criterio como medida de impulso a la mediación, verdaderamente se podría avanzar en la implantación efectiva de la mediación en España, si bien consideramos que paralelamente sería igualmente necesaria una política de potenciación y profesionalización de la mediación. En definitiva, para implementar de forma efectiva la mediación en nuestro país se ha de fomentar e impulsar este método, en su vertiente complementaria a la vía jurisdiccional, para avanzar con ello en la búsqueda de un nuevo modelo de Justicia integral.

${ }^{1}$ Para mayor información al respecto, consúltese: Carrasco Durán, M. (2018) El derecho a la tutela judicial efectiva sin indefensión, Thomson Reuters-Aranzandi.

\section{Referencias}

Azcárraga Monzonís, C. (2013). Impulso de la mediación en Europa y España y ejecución de acuerdos de mediación en la Unión Europea como documentos públicos con fuerza ejecutiva. Revista electrónica de estudios internacionales, (25).

Azcárraga Monzonís, C. (2016). El (limitado) impacto de la directiva sobre mediación en asuntos civiles y mercantiles y la mediación obligatoria como medida de promoción en S. Barona Vilar (Ed.), Mediación, Arbitraje y Jurisdicción en el nuevo paradigma de Justicia (pp. 103-117). Civitas-Thomson Reuters.

Barona Vilar, S. (2010). Solución extrajurisdiccional de conflictos con ojos de mujer: la incorporación de las ADR en el ordenamiento jurídico español en K. Etxebarría Estankona e I. Ordeñana Gezuraga (Dirs.), La resolución alternativa de conflictos. Segunda edición de las jornadas "Justicia con ojos de mujer" celebradas en la Facultad de Derecho de la UPV/EHU el 26 de noviembre de 2009. Argitalpen Zerbitzua S. E. 
Barona Vilar, S. (2011). Las ADR en la justicia del siglo XXI, en especial la mediación. Revista de Derecho Universidad Católica del Norte, (1).

Barona Vilar, S. (2013). Mediación en asuntos civiles y mercantiles en España. Tras la aprobación de la Ley 5/2012, de 6 de julio. Tirant Lo Blanch.

Barona Vilar, S. (2014). Integración de la mediación en el moderno concepto de Acces to Justice. Luces y sombras en Europa. InDret. http://www.indret.com/pdf/1092.pdf

Barona Vilar, S. (2018). Nociones y principios de las ADR (solución extrajurisdiccional de conflictos). Tirant lo Blanch.

Barona Vilar, S. (2018). Retrato de la justicia civil en el siglo XXI: ¿caos o una nueva estrella fugaz? Revista Boliviana de Derecho, (25).

Barona Vilar, S. (2020). Justicia civil post-coronavirus, de la crisis a algunas de las reformas que se avizoran. Actualidad Jurídica Iberoamericana, (12 bis).

Blohorn-Brenneur, B. y Soleto Muñoz, H. (2019). La Mediación para todos: la Mediación en el ámbito civil e intrajudicial. Aranzadi.

Comunicación poder Judicial (16 de junio de 2020). El Pleno del órgano de gobierno de los jueces aprueba el plan de choque del CGPJ para la reactivación tras el estado de alarma. http://www.poderjudicial.es/cgpj/es/Poder-Judicial/Consejo-Generaldel-Poder-Judicial/Oficina-de-Comunicacion/Archivo-de-notas-de-prensa/ElPleno-del-organo-de-gobierno-de-los-jueces-aprueba-el-plan-de-choque-delCGPJ-para-la-reactivacion-tras-el-estado-de-alarma

García García, L. (2003). Mediación familiar. Prevención y alternativa al litigio en los conflictos familiares. Dykinson.

García Villaluenga, L. (2010). La mediación a través de sus principios. Reflexiones a la luz del anteproyecto de Ley de mediación en asuntos civiles y mercantiles. Revista general de legislación y jurisprudencia, (4).

Martin Diz, F. (2014). Del derecho a la tutela judicial efectiva o de la Justicia. Revista Europea de Derechos Fundamentales, (23).

Martin Diz, F. (2014). Mediación en derecho privado: nuevas perspectivas prácticas. Revista General de Derecho Procesal, (33).

Martin Diz, F. (2019). El derecho fundamental a justicia: Revisión integral e integradora del derecho a la tutela judicial efectiva. Revista de derecho político, (106).

Moreno Catena, V. (2017). La resolución jurídica de conflictos en H. Soleto Muñoz (Dir.), Mediación y solución de conflictos: técnicas y ámbitos (p. 50). Tecnos.

Otero Parga, M. (2007). Ventajas e inconvenientes de la mediación en H. Soleto Muñoz y M. Otero Parga (Coords.), Mediación y solución de conflictos: habilidades para una necesidad emergente. Tecnos.

Pardo Iranzo, V. (2014). La ejecución del acuerdo de mediación. Aranzadi.

Prats Albentosa, L. (2011). Desjudicialización (I): el proyecto de Ley de Mediación en Asuntos Civiles y Mercantiles. Diario La Ley, (7625).

Redorta Lorente, J. (2009). La justicia del futuro. Simposio sobre Tribunales y Mediación. Nuevos caminos para la Justicia. Comunicaciones. GEMME.

Soleto Muñoz, H. (2009). La mediación: método de resolución alternativa de conflictos en el proceso civil español. Revista eletrônica de Direito Processual, (3), pp. 6688.

Soleto Muñoz, H. (2017). El proceso de mediación en H. Soleto Muñoz (Dir.), Mediación y solución de conflictos: técnicas y ámbitos. Tecnos.

Vázquez De Castro, E. y García Villaluenga, L. (2013). La mediación civil en España: luces y sombras de un marco normativo. Política y Sociedad, (50).

Vilalta Nicuesa, A. (2009). Una aproximación al derecho extranjero en materia de mediación en P. Casanovas, y M. Poblet (Eds.), Materiales del Libro Blanco de la Mediación en Cataluña. Generalitat de Catalunya, Departament de Justicia, Centre d’Estudis Jurídics i Formació Especialitzada. 